\section{Construction of Phagemid Display Libraries with PCR-amplified Immunoglobulin Sequences}

\author{
Holly H. Hogrefe' ${ }^{1}$ and \\ Bob Shopes ${ }^{2}$
}

\footnotetext{
${ }^{1}$ Stratagene Cloning Systems, La Jolla, California 92037;

${ }^{2}$ Tera Biotechnology, La Jolla, California 92037
}

The expression of active antibody fragments in Escherichia coli has led to significant advances in the identification of antigen-binding clones using molecular biological techniques. ${ }^{(1-7)}$ When coupled with the recently developed phage display technology, ${ }^{(8,9)} \mathrm{Fab}$ fragment libraries containing up to $10^{8}$ unique specificities may be readily constructed and screened. Using the phage display screening technique, clones that bind to a particular antigen may be isolated by enriching (biopanning) libraries of recombinant phagemid that display Fab on the surface as a fusion with the minor coat protein cpIII of M13. ${ }^{(10-17)}$ The phagemid contain the light-chain and heavychain genes of the displayed Fab, thereby allowing further characterization and manipulation of antigen-binding activity at the molecular level. ${ }^{(18-20)}$

The diversity of the immunoglobulin repertoire may be effectively captured by PCR. Light- and heavy-chain genes are amplified by PCR from reverse-transcribed transcripts of the rearranged immunoglobulin genes. To construct comprehensive Fab libraries, exhaustive sets of PCR primers have been designed by us ${ }^{(10,11 \text {; this article) }}$ and others ${ }^{(3,17,21-26)}$ that correspond to the amino terminus of the variable regions of known immunoglobulins and the carboxyl terminus of the $\mathrm{CH} 1$ domains of the heavy-chain isotypes or the $\mathrm{k}$ and $\lambda$ light chains.

A number of strategies have been devised to recombine diverse repertoires of light- and heavy-chain sequences randomly into a bicistronic operon expressing Fab. These include sequential cloning, ${ }^{(12)}$ PCR with a linker primer, ${ }^{(17)}$ splice overlap extension, ${ }^{(27)}$ ligating together two restriction-digested vectors, each encoding a single chain ${ }^{(6,7)}$ and, finally, ligating the light- and heavy-chain $\mathrm{Fd}$ sequences together at a rare nonpalindromic restriction site. ${ }^{(10,11)}$ The latter approach represents an efficient, one-step cloning method that avoids potential unnecessary skewing of the immunoglobulin repertoire. With combinatorial approaches, it has been possible to construct Fab libraries containing up to $10^{8}$ unique clones, the limiting factor being transformation of bacteria by plasmid or by infection. Methodologies for constructing larger libraries on the theoretical scale of $10^{12}$ clones are currently under development and may permit isolation of rare specificities with high affinity without the necessity of prior immunization.

\section{MATERIALS AND METHODS}

\section{Strategy}

We have developed a simplified, but efficient, method for constructing comprehensive phage display libraries of human Fab fragments (Fig. 1). A schematic of the SurfZAP lambda vector (Stratagene Cloning Systems) ${ }^{(10)}$ with a Fab gene cassette is shown in Figure 2. In our Fab fragment library constructs, the heavy-chain $\mathrm{Fd}$ portion $\left(\mathrm{V}_{\mathrm{H}}-\mathrm{D}-\mathrm{J}-\mathrm{C}_{\mathrm{H}} 1\right.$ domains) is expressed as a fusion with the M13 minor coat protein cpIII, although light-chain-cpIII fusions have been used successfully by others. ${ }^{(16)}$ The light-chain and Fd-cpIII sequences are transcribed as a polycistronic message from the lac $Z$ promoter. The SurfZAP vector encodes a ribosome-binding site (RBS) for translation of the light chain and a partial pelB leader sequence to direct the light chain to the periplasm. The Fab gene cassette includes the remaining carboxy-terminal portion of the pelB leader, followed by the light-chain gene sequence, a stop codon, a second RBS, a downstream pelB leader sequence and, finally, the Fd gene sequence.

The Fab gene cassette is constructed as described in Figure 3. Light-chain and Fd sequences are amplified independently and then randomly ligated together at a common Sfil site prior to cloning into SurfZAP. An Sfil restriction site was chosen because its 8 -base recognition sequence occurs very 
PCR Amplify HC and LC genes

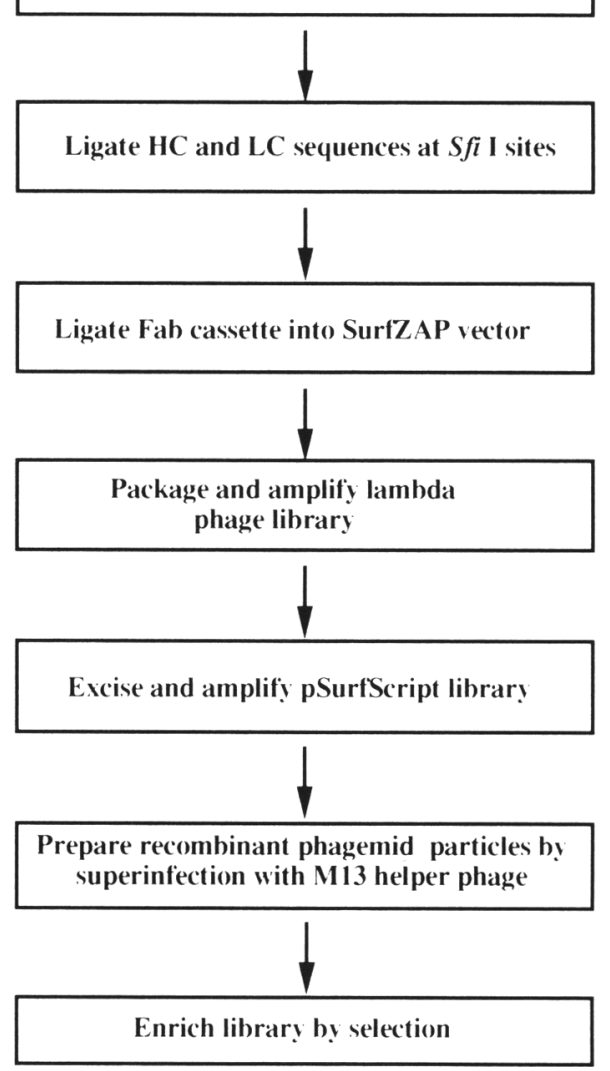

FIGURE 1 Flowchart for the construction of a phagemid display antibody library in the SurfZAP vector.

infrequently in antibody-coding regions and it contains a 5-bp nonpalindromic center. Sfil cleavage gives rise to 3-bp non-self-complementary ends, thereby favoring light chain to Fd ligation over light chain to light chain or Fd to Fd ligation. This simplified method obviates the need for constructing more than one library, ${ }^{(6,7)}$ multiple cloning steps, ${ }^{(12-14)}$ or additional $\mathrm{PCR}^{(17)}$ as required in other combinatorial approaches.

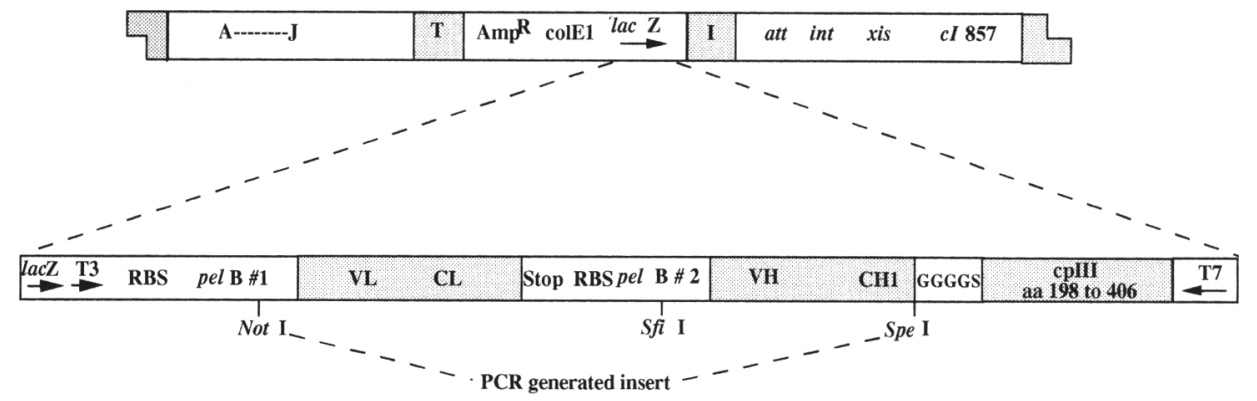

FIGURE 2 The SurfZAP $\lambda$ vector containing a Fab gene cassette insert. The SurfZAP $\lambda$ vector contains the I (initiator) and $\mathrm{T}$ (terminator) sequences of the $\mathrm{fl}$ origin for excision of the pSurfScript plasmid. ${ }^{(30)}$ The left arm also contains the lacZ promoter, RBS, and a partial pelB leader sequence; the right arm encodes a 5 -amino-acid spacer sequence $\left.\left[(\mathrm{Gly})_{4}-\mathrm{Ser}\right)\right]$, amino acids 198-406 of cpllI, and a stop codon. Construction of the Fab gene cassette is shown in Fig. 3. After ligation, the vector expresses a soluble light chain and an Fd/cplII fusion protein as a dicistronic message from the lac $Z$ promoter. 

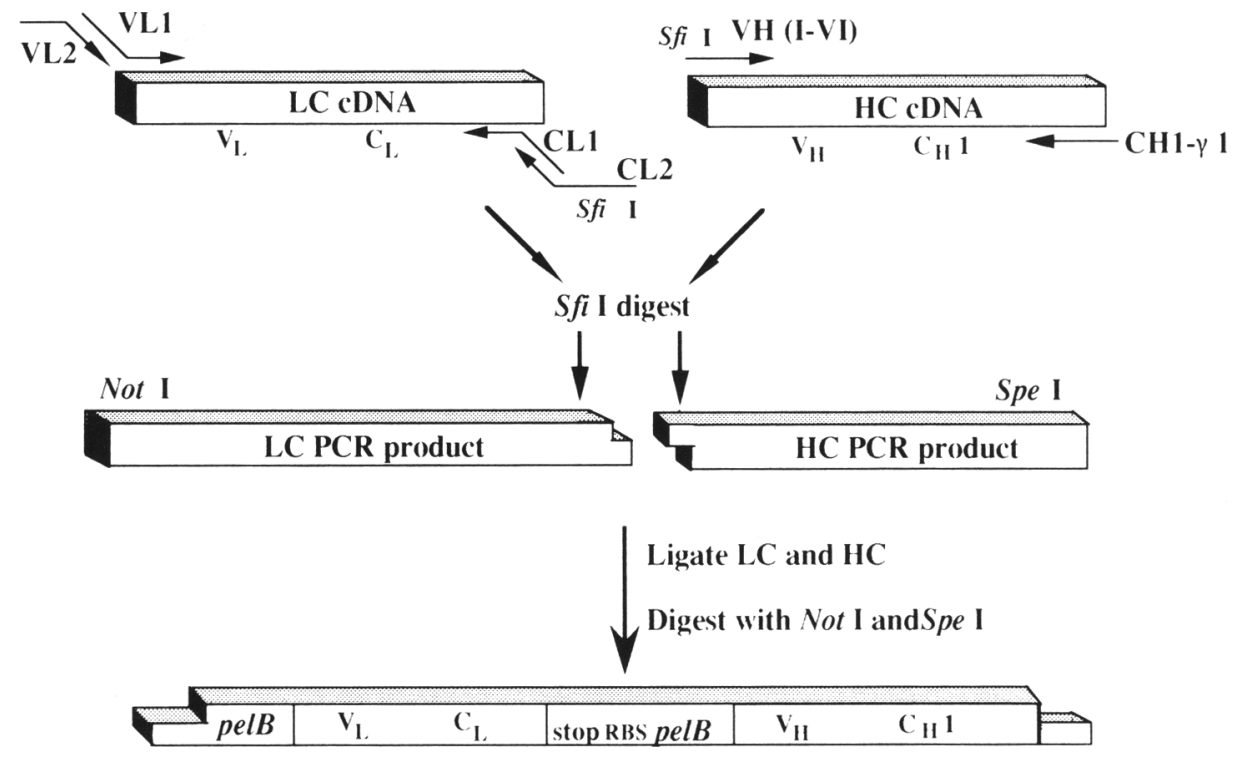

FIGURE 3 Preparation of the light-chain-Fd insert for the SurfZAP vector. Light-chain and Fd sequences are amplified by PCR from B-cell cDNA using the primer sets listed in Table 1. The PCR primers introduce SfiI sites used to combine light-chain and Fd sequences randomly, NotI and Spel cloning sites, the light-chain stop codon, and a RBS and pelB leader sequence for translation and translocation of the Fd-cpIII fusion protein.

To prepare the Fab gene cassette, light-chain and Fd sequences are amplified independently by PCR from cDNA of B cell mRNA. The PCR primers were designed to hybridize to framework or constant-region domain genes of known human immunoglobulins ${ }^{(28)}$ and are listed in Table 1 . We have similarly designed a full set of family-specific mouse PCR primers (data not shown). Kappa light chains are amplified from cDNA with the VL1-K and CL1-k primer pairs, and these genes are then reamplified with the VL2 and CL2 primers to add restriction sites and leader sequences. The VL1-k primers hybridize to the framework 1 codons of the different $\kappa$ light-chain families, and the VL2 primer introduces a NotI cloning site and the carboxy-terminal portion of the pelB leader. The CL1- $k$ primer hybridizes to the $3^{\prime}$ end of the $\kappa$ light-chain constant domain gene and, in combination with CL2, introduces a stop codon, the RBS and pelB leader sequence for the downstream Fd-cpIII fusion protein, and the SfiI common restriction site. Conservative changes were made in the nucleotide sequence of the downstream pelB leader (partially encoded by primer CL2) to minimize recombination with the upstream pelB leader sequences. For the construction of $\lambda$ light-chain libraries, $\lambda$ lightchain genes can be amplified in a similar fashion with family-specific VL1-K and CL1-k primer pairs (data not shown).

The Fd portion $\left(\mathrm{V}_{\mathrm{H}}\right.$-D-J-C $\left.\mathrm{C}_{\mathrm{H}} 1\right)$ of heavy chain genes is amplified by PCR with primer sets designated $\mathrm{VH}-(\mathrm{I}-\mathrm{VI})$ and $\mathrm{CH} 1-\gamma 1$ or $\mathrm{CH} 1-\mu$. The $\mathrm{VH}$ primers hybridize to the framework 1 region of the different heavy-chain families and add the Sfil site, which will be used to assemble the Fab gene cassette. The $\mathrm{CH} 1$ primers introduce a downstream Spel cloning site and hybridize to the 3' end of the genes encoding the first constant region domains.

To increase diversity of the combinatorial libraries, the $\kappa$ and $\lambda$ light-chain genes are amplified by PCR independently, using all possible combinations of each family-specific and constant region-specific primer. Similarly, separate PCR reactions are performed for each combination of family-specific VH primer and constant region primer to generate a comprehensive collection of Fd sequences. All of the light-chain PCR products are pooled and digested 
TABLE 1 Primers Used for PCR Amplification of Human Heavy- and Light-chain Genes

\begin{tabular}{|c|c|}
\hline \multicolumn{2}{|c|}{ A. Human heavy-chain primers } \\
\hline VH-I & 5' - TCGCGGCCCAACCGGCCATGGCCCAGGTGC A GCTGGTGCAG-3' \\
\hline VH-II & 5'- TCGCGGCCCAACCGGCCATGGCCCAGGTCA A CTAAGGGAG-3' \\
\hline VH-III & 5'- TCGCGGCCCAACCGGCCATGGCCCAGGTGC A GCTGGTGGAG-3' \\
\hline VH-IV & 5' - TCGCGGCCCAACCGGCCATGGCCCAGGTGC A GCTGCAGGAGTCG-3' \\
\hline VH-V & 5'- TCGCGGCCCAACCGGCCATGGCCCAGGTGC A GCTGGTGCAG-3' \\
\hline VH-VI & 5' - TCGCGGCCCAACCGGCCATGGCCCAGGTAC A GCTGCAGCACTCA-3' \\
\hline $\mathrm{CH} 1-\gamma$ & 5'- CGGACTAGTACAAGATTTGGGCTCTGCTTT-3' \\
\hline $\mathrm{CH} 1-\mu$ & 5' - AGCATCACTAGTGGCAATCACTGGAAGAGG-3' \\
\hline \multicolumn{2}{|c|}{ B. Human light-chain primers } \\
\hline VL1-кI & 5'- GCCCAACCAGCCATGGCCGACATCCAGATG A CCCAGTC-3' \\
\hline VL1-kII & 5'- GCCCAACCAGCCATGGCCGATATTGTGATG A CTCAG-3' \\
\hline VL1-кDeg. & 5'- GCCCAACCAGCCATGGCCGATATTGTGATG A CCCAGTCT-3' \\
\hline VL2 & 5'-GAAATCACTCCCAATTAGCGGCCGCTGGAT T GTTATTACTCGCTGCCC \\
\hline CL1-K & $\begin{array}{l}\text { AACCAGCCATGGCC-3' } \\
\text { 5'- ATGACTGTCTCCTTGAAGCTTTCATTAACA C TCTCCCCTGTTGAAGCT } \\
\text { CTTTGTGACGGGCGAACTC-3' }\end{array}$ \\
\hline CL2 & 5'- CATGGCCGGTTGGGCCGCGAGTAATAACAA T CCAGCGGCTGCCGTAGG \\
\hline & CAATAGGTATTTCATTATGACTGTCTCCTTG-3' \\
\hline
\end{tabular}

(A) The 3' end of the VH-I-VI primers is homologous to the sense strand of the first few codons of the six $V_{H}$ families designated in Ref. 28. The $5^{\prime}$ end of the VH primers incorporates an Sfil restriction site (underlined) and encodes the $3^{\prime}$ half of the pelB leader sequence 2 . The $3^{\prime}$ end of the $\mathrm{CH} 1-\gamma 1$ and the $\mathrm{CH} 1-\mu$ primers are homologous to the antisense strand of the last few codons of the $C_{H} 1$ domain gene of human $\operatorname{IgG}_{1}$ and human IgM, respectively. A Spel restriction site (underlined) is incorporated in the $\mathrm{CH} 1$ primers.

(B) The $3^{\prime}$ end of the VL1- $\kappa$ primers is homologous to the sense strand of the -4 to +8 codons of $V_{L} \kappa$ families I and II and the consensus human $V_{L}$ sequence compiled in Ref. 28. The VL2 primer adds a portion of the first pelB leader sequence and incorporates a NotI restriction site (underlined). The $5^{\prime}$ end of the CL1-K primer is homologous to the antisense strand of the last codons of human $\kappa$ from Ref. 28. The CL2 primer adds the 5 ' portion of the second pelB leader sequence 2 and incorporates an Sfil restriction site (underlined).

with Sfil and then ligated with the similarly pooled and digested Fd PCR products to generate the Fab gene cassette. Conversely, each PCR reaction may be digested separately so that each selected light-chain PCR product can be ligated with selected Fd products. This latter approach allows one to monitor and regulate the composition of a combinatorial library, which may be of particular interest when the immune response to an antigen is known and dominated by one family of antibody genes or class of immunoglobulins. For example, low-affinity, poly- or self-reactive Fab clones may be isolated more successfully from libraries containing heavy-chain IgM sequences. ${ }^{(29)}$

The Fab gene cassette is digested with NotI and SpeI and cloned into SurfZAP so that the Fd forms a fusion with a truncated version (amino acids 198-406) of the M13 minor coat protein cpIII (Fig. 2). The primary SurfZAP library is packaged into lambda phage and introduced into bacterial cells by infection. The primary library is amplified by lytic growth to increase representation of each clone. The SurfZAP lambda vector was designed with a split f1 origin to allow subsequent in vivo excision of the pSurfScript SK(-) phagemid with helper phage. ${ }^{(30)}$ The excisable portion of the pSurfScript plasmid contains the ampicillin-resistance gene, the ColE1 origin, and the Fab gene cassette, which is transcribed as bicistronic mRNA from the lacZ promoter. In cells harboring the pSurfScript plasmid, the pelB leader sequences direct the light-chain and the Fd-cpIII fusion protein across the inner bacterial membrane into the periplasmic space. Functional Fab molecules assem- 
ble in the periplasm with the cpIII portion of the Fd-cpIII fusion embedded in the inner membrane. When these cells are superinfected with M13 helper phage, phagemid particles are generated that bear a Fab molecule on the surface and contain the pSurfScript DNA encoding the displayed antigenic specificity. Libraries of phagemid displaying Fab fragments may then be subjected to biopanning to enrich for antibody clones with desired binding activities.

\section{Preparation of B-cell CDNA}

Successful cloning of Fabs with the desired specificity and affinity is greatly influenced by the source of mRNA used in the cDNA synthesis. Ideally, B-cell RNA should be recovered from actively immunized humans, rabbits, or mice. Lymph node, spleen, and bone marrow have been used as sources of activated B cells. For example, spleens may be harvested from immunized mice 3-5 days after the last booster immunization, similar to the preparation of hybridomas. ${ }^{(31)}$ For constructing human Fab libraries from immunized donors, peripheral blood is likely to be the only practical source available. Lymphocytes are isolated from $50 \mathrm{ml}$ of heparinized blood with HistoPaque (Sigma) 5-6 days postboost, when the concentration of antigen-specific B cells in the circulation is maximal. ${ }^{(32,33)}$ When actively immunized human donors are not available, spleen, bone marrow, and/or lymph node tissue should be used whenever ethically possible because the number of activated $B$ cells will be low in the peripheral blood. If peripheral blood from human donors not actively immunized must be used, then the frequency of antigen-specific clones may be increased by in vitro immunization ${ }^{(34)}$ or by including IgM Fd sequences in the Fab gene cassette, which are typically polyreactive and of lower affinity. ${ }^{(29)}$

For the experiments described here, total RNA was isolated from human peripheral blood (RNA Isolation kit, Stratagene) and stored in $\mathrm{EtOH}$ at $-20^{\circ} \mathrm{C}$ until use. Total RNA (10-20 $\mu$ g) was annealed to $400 \mathrm{ng}$ of oligo(dT) (for light chain) or the appropriate $\mathrm{CH} 1$ primer (for $\mathrm{Fd}$ ) in $70 \mu \mathrm{l}$ of DEPC-treated water by heating the reactants at $70^{\circ} \mathrm{C}$ for $5 \mathrm{~min}$ and then cooling slowly to $37^{\circ} \mathrm{C}$. cDNA synthesis was performed by adding the following reagents to the primed RNA: $20 \mu$ l of $5 \times$ Moloney reverse transcriptase buffer (GIBCO-BRL), $5 \mu \mathrm{l}$ of $1 \mathrm{M}$ DTT, $4 \mu \mathrm{l}$ of dNTP mix ( $25 \mathrm{~mm}$ each; Stratagene), and $1 \mu \mathrm{l}(80$ units) $\mathrm{RNase}^{-}$Moloney LV reverse transcriptase (GIBCO-BRL). First-strand synthesis reactions were incubated at $37^{\circ} \mathrm{C}$ for $60 \mathrm{~min}$ and at $42^{\circ} \mathrm{C}$ for $30 \mathrm{~min}$. RNase $\mathrm{H}$ ( 2 units) was added, and the mixture was incubated at $55^{\circ} \mathrm{C}$ for an additional $10 \mathrm{~min}$. Enzymes were removed with StrataClean (Stratagene) and stored at $4^{\circ} \mathrm{C}$ for up to 2 weeks.

\section{PCR Amplification of Light-Chain and Fd Sequences}

Human light-chain and Fd sequences were amplified by PCR in a series of individual reactions that employed combinations of the forward human family-specific primers and reverse human constant region primers (e.g., each $\mathrm{VH}$

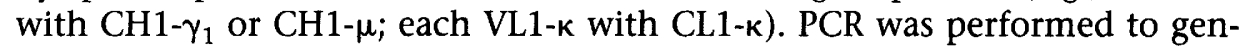
erate a total of $\geqslant 1 \mu \mathrm{g}$ of each light-chain product and $\geqslant 1 \mu \mathrm{g}$ of each $\mathrm{Fd}$ product. For amplification of light-chain sequences, reagents were added in the following order to $0.5-\mathrm{ml}$ PCR tubes: water to $100 \mu$ l final volume, $10 \mu \mathrm{l}$ of $10 \times$ Taq buffer, $0.8 \mu$ l of $25 \mathrm{~mm}$ each dNTP, $100 \mathrm{ng}$ of VL1-к primer, 100 ng of CL1-к primer, $5 \mu \mathrm{l}$ of cDNA [oligo(dT)-primed], and 2.5 units of Taq polymerase. Light-chain products were reamplified with $100 \mathrm{ng}$ of VL-2 and $100 \mathrm{ng}$ of CL-2 to introduce additional required sequences. Fd PCR samples were prepared similarly except that $100 \mathrm{ng}$ of $\mathrm{VH}$ primer, $100 \mathrm{ng}$ of $\mathrm{CH} 1-\gamma_{1}$ (or $\mathrm{CH} 1-\mu)$ primer, and $5 \mu \mathrm{l}$ of heavy-chain CDNA (CH1-primed) were used. The reaction mixtures were overlaid with mineral oil and subjected to PCR under 
the following conditions: $94^{\circ} \mathrm{C}$ for $5 \mathrm{~min}, 54^{\circ} \mathrm{C}$ for $5 \mathrm{~min}$; then for 40 cycles, $72^{\circ} \mathrm{C}$ for $3 \mathrm{~min}, 93^{\circ} \mathrm{C}$ for $1.5 \mathrm{~min}, 54^{\circ} \mathrm{C}$ for $2.5 \mathrm{~min}$; followed by $72^{\circ} \mathrm{C}$ for 10 min. A 10- $\mu$ l amount of each PCR reaction was analyzed by agarose gel electrophoresis to verify successful amplification of the $\sim 700$-bp light-chain and Fd gene sequences. PCR controls consisting of all reagents except the firststrand reaction were performed to verify that PCR amplification was template dependent.

\section{Preparation and Cloning of the LC/Fd Insert}

The Fd PCR products and light-chain PCR products were extracted with phenol/chloroform and chloroform. Sodium acetate was added to a final concentration of $0.3 \mathrm{M}$, and the DNA was precipitated with 2.5 volumes of ethanol. DNA pellets were washed with $70 \%$ ethanol, dried, and resuspended in $100 \mu l$ of water. The light-chain and Fd PCR products were digested separately with Sfil by adding the following reagents to $\sim 1 \mu \mathrm{g}$ of each DNA sample: water to a final volume of $500 \mu \mathrm{l}, 50 \mu \mathrm{l}$ of $10 \times$ Optimal Buffer \#3 (Stratagene), and $15 \mu$ l of SfiI (60 units) (New England BioLabs). The PCR products were digested at $50^{\circ} \mathrm{C}$ for $2 \mathrm{hr}$. Efficiency of the Sfil digestion was assessed by adding a small aliquot of the PCR product digest (one-fiftieth volume), just after enzyme addition, to $0.2 \mu \mathrm{g}$ of a test plasmid that contained an SfiI restriction site. If the test plasmid could be cut, it was assumed that the PCR product was free of potential contaminants that might inhibit digestion and that the enzyme was in sufficient excess to cut the PCR product completely. The SfiI-digested light-chain and Fd PCR products were purified by preparative gel electrophoresis using 1\% SeaKem (FMC) agarose gels. DNA was eluted with GeneClean (Bio101) into $10 \mu \mathrm{l}$ of water, and the concentrations were determined with ethidium bromide plates. ${ }^{(35)}$

Equimolar amounts of the light-chain and Fd PCR products were ligated together in a small volume at the common SfiI restriction site. The following components were added in order to a $0.5-\mathrm{ml}$ microcentrifuge tube: water to a final volume of $10 \mu \mathrm{l}, 1 \mu \mathrm{l}$ of $10 \times$ ligase buffer, $1 \mu \mathrm{l}$ of $10 \mathrm{~mm}$ rATP, $0.1-1 \mu \mathrm{g}$ of Sfil-digested Fd PCR product, 0.1-1 $\mu \mathrm{g}$ (equimolar with Fd PCR product) of Sfil-digested light-chain PCR product, and $0.5 \mu \mathrm{l}$ ( 2 units) of T4 DNA ligase (Stratagene). The ligation reaction was incubated at $4^{\circ} \mathrm{C}$ overnight. Ligation was verified by the presence of a $1.4-\mathrm{kb}$ band on a $1 \%$ agarose gel.

The ligation reaction was extracted with phenol/chloroform and chloroform, and the DNA was precipitated with $0.3 \mathrm{~m}$ sodium acetate $/ 70 \%$ ethanol. The DNA pellet was washed with $70 \%$ ethanol, dried, and resuspended in 100 $\mu l$ of water. SpeI digestion of the light-chain-Fd insert was performed by incubating 3 units of SpeI (Stratagene) per 100 ng of DNA in $200 \mu l$ of the recommended buffer. After $1 \mathrm{hr}$ of incubation at $37^{\circ} \mathrm{C}, 5 \mathrm{M} \mathrm{NaCl}$ was added to bring the final molarity to $150 \mathrm{~mm} \mathrm{NaCl}$. Three units of NotI (New England BioLabs) was added, and the digestion was allowed to proceed for $1 \mathrm{hr}$ at $37^{\circ} \mathrm{C}$. Efficiencies of the SpeI and NotI digestions were determined by adding a small aliquot of the ligation mixture digest (one-fiftieth volume), just after enzyme addition, to $0.2 \mu \mathrm{g}$ of supercoiled control plasmids that contain either SpeI or NotI restriction sites. The double-digested light-chain-Fd insert was gel purified and quantified as described above.

The Fab gene cassette was cloned into the NotI-SpeI double-digested SurfZAP vector (Stratagene) (water to a final volume of $5 \mu \mathrm{l}, 0.5 \mu \mathrm{l}$ of $10 \times$ ligase buffer, $0.5 \mu \mathrm{l}$ of $10 \mathrm{~mm}$ rATP, $34 \mathrm{ng}$ of the light-chain-Fd insert, $1 \mu \mathrm{g}$ of the SurfZAP vector, and 2 units of T4 DNA ligase). Ligation was allowed to proceed overnight at $4^{\circ} \mathrm{C}$.

Preparation of the Phage Display Library

The ligation reactions were packaged with Gigapack II packaging extracts 
(Stratagene). The resulting primary libraries were amplified by lytic growth to increase the representation of each Fab clone. Amplified libraries were converted to pSurfScript phagemid libraries by in vivo mass excision with ExAssist helper phage (Stratagene). ${ }^{(11,36)}$ The excised phagemid libraries were then amplified in SOLR host cells (Stratagene), and recombinant phagemid particles for biopanning were prepared by superinfection with VCSM13 helper phage (Stratagene) as described below.

\section{RESULTS}

\section{Fab Library Construction}

Representative results obtained when PCR amplifying light-chain and heavychain Fd sequences are shown in Figure 4. In most cases, a single band is observed migrating at $\sim 700 \mathrm{bp}$. Typically, the amount of PCR product obtained varies for each family-specific variable region and constant region primer pair depending on the particular cDNA sample employed. Figure 5 shows representative results obtained when the Sfil-digested light-chain and Fd PCR products are ligated together. Observed ligation efficiencies are routinely $30-50 \%$. The Fab gene cassette is then digested with NotI and SpeI and

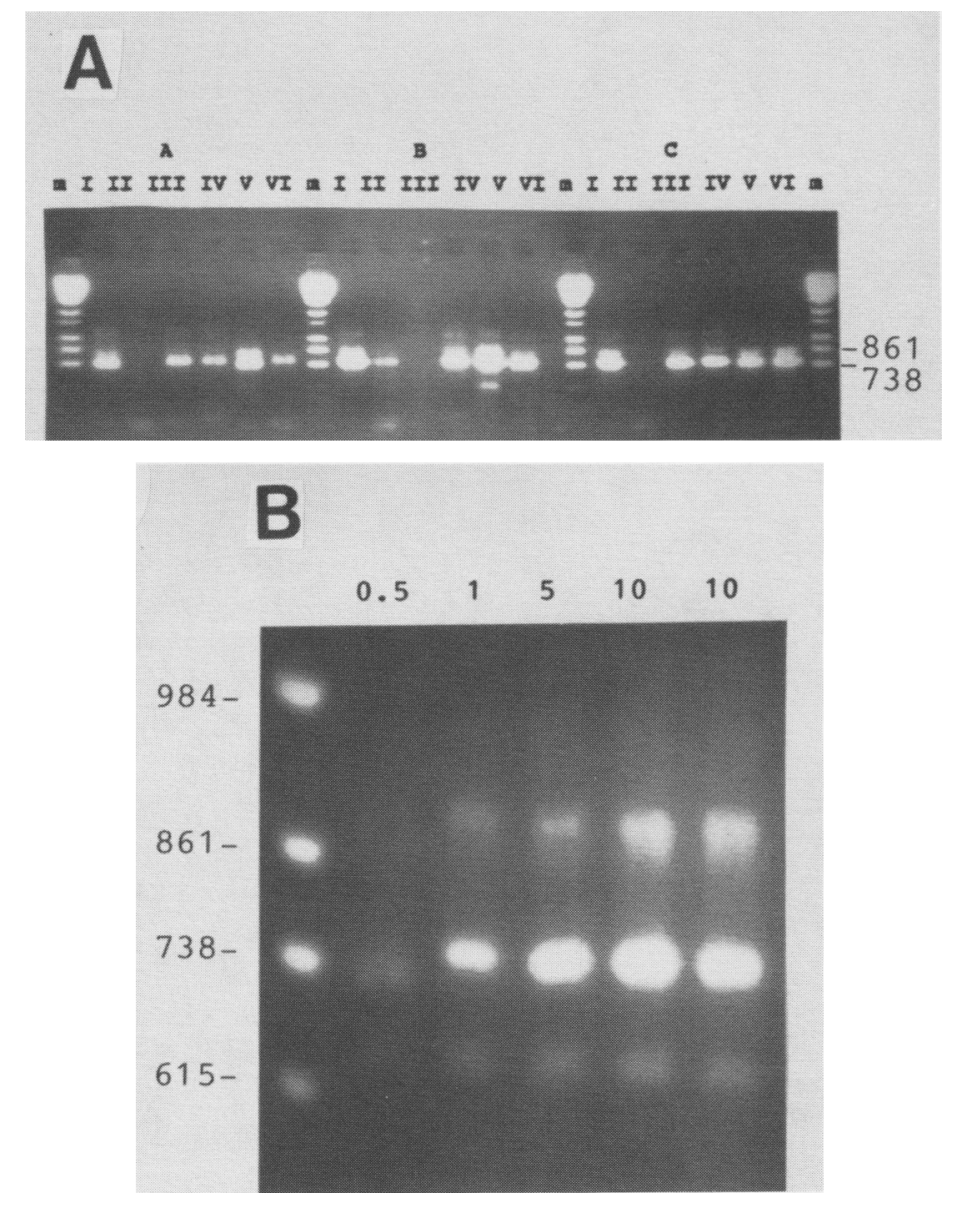

FIGURE 4 PCR amplification of Fd and light-chain sequences. cDNA was prepared as described in the text from human peripheral blood and lymph node tissue. $(A)$ Fd sequences were amplified by PCR with the $\mathrm{VH}(\mathrm{I}-\mathrm{VI})$ and $\mathrm{CH} 1-\gamma 1$ primers using CDNA prepared from three different donors (A, B, C). DNA standards were run in lanes $m$, and the molecular weights are given in base pairs.

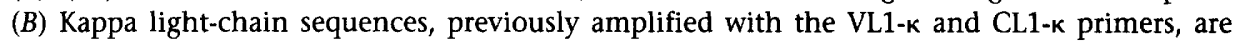
reamplified with the VL2 and CL2 primers. The amount of light-chain product obtained after 10 rounds of PCR is shown using 0.5-, 1-, 5-, and 10- $\mu$ l aliquots of the original light-chain PCR product as template. Molecular weight markers were run in the first lane on the left. 


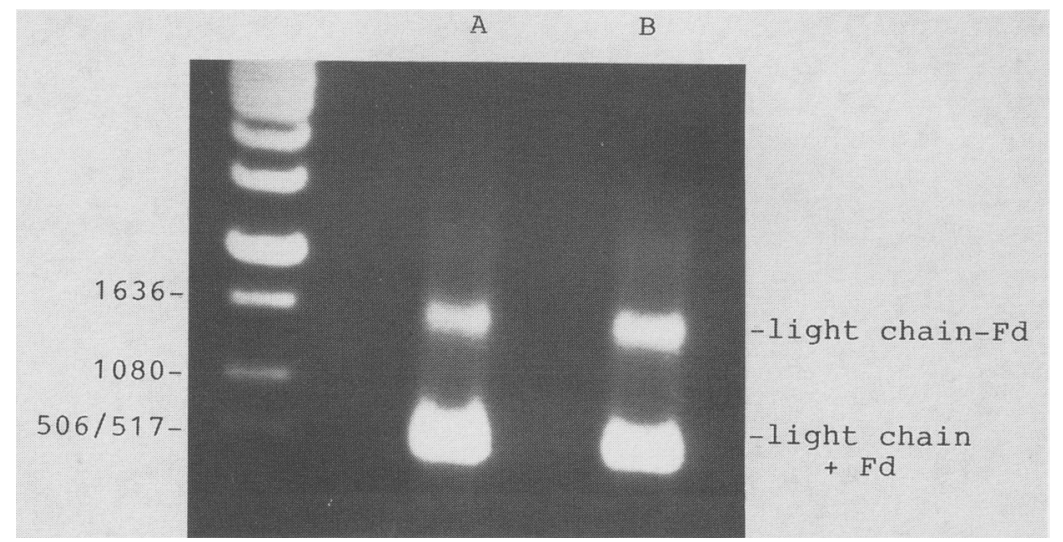

FIGURE 5 Ligation of light-chain and heavy-chain (Fd) sequences at the common Sfil restriction site. Light-chain and Fd PCR products amplified from two different cDNA sources $(A, B)$ were digested with Sfil, gel isolated, and ligated together as described in the text. The intended lightchain-Fd cassette migrates at $\sim 1400$ base pairs, while the unligated light chain and Fd PCR products comigrate at $700 \mathrm{bp}$. The molecular weights of DNA standards, run in the first lane on the left, are given in base pairs.

cloned into the SurfZAP lambda vector. Packaging of the SurfZAP libraries with GigaPack II packaging extracts (Stratagene) yields primary lambda libraries that consist of between $10^{6}$ and $10^{8}$ unique Fab clones per microgram of vector.

\section{Optimization of the Preparation of Phagemid Displaying Fab}

Once the SurfZAP $\lambda$ library has been constructed, it is converted to the pSurfScript phagemid library by in vivo mass excision. ${ }^{(10,11,30,36)}$ We have shown previously that lytic amplification and mass excision of lambda phage libraries, or liquid amplification of the phagemid libraries, do not appear to alter significantly the representation of antigen-binding Fab clones when these procedures are performed as described. ${ }^{(11)}$ Phagemid particles for biopanning are then generated by superinfection of pSurfScript-harboring cells with M13 helper phage. Initially, single-stranded rescues were performed under standard conditions by infecting phagemid-harboring cells with VCSM13 at a multiplicity of infection (m.o.i.) of 10:1 and allowing the infection to proceed overnight at $37^{\circ} \mathrm{C}$. The need for optimizing the single-stranded rescue procedure became apparent when we observed that a single phagemid Fab clone, reamplified on several different occasions, gave inconsistent results when reacted with antigen in an ELISA.

To optimize the single-stranded rescue of phagemid, we examined the effects of varying superinfection m.o.i., growth temperature, time of addition of helper phage, addition of various concentrations of glucose, and incubation time on the antigen-binding reactivity of the phagemid particles produced. An increase in antigen-binding activity for phagemid displaying a Fab clone was observed when single-stranded rescues were stopped prior to the cells achieving stationary phase. In rescues carried out after cell growth reached stationary phase (e.g., overnight at $37^{\circ} \mathrm{C}$ ), we consistently observed a drop in antigen-binding activity with no significant change in phage titer (see Fig. $6,37^{\circ} \mathrm{C}$ incubation). These results suggested that the Fab-cpIII fusion protein may be susceptible to proteolytic degradation. Maximal antigen-binding activity was observed [adjusting the phagemid particle concentration based on plaque-forming units (pfu)] when pSurfScript-containing cells were infected in early log phase $\left(\leqslant 0.1\right.$ at $\left.\mathrm{OD}_{600}\right)$ at an m.o.i. of $\geqslant 2: 1$ helper phage/ cells (data not shown). The addition of glucose, which helps to propagate Fab clones toxic to $E$. coli by inhibiting transcription from the lacZ promoter, was 
A

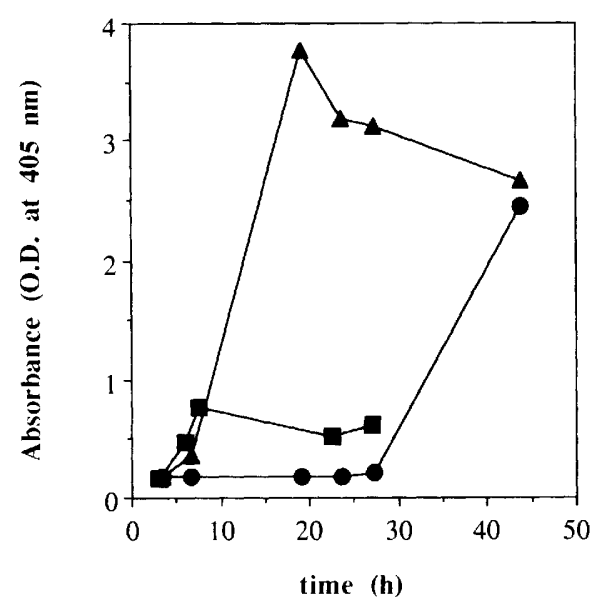

B

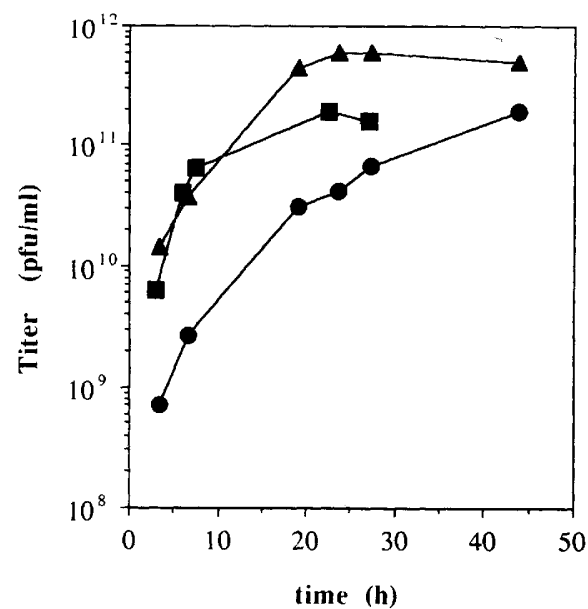

FICURE 6 Optimization of the single-stranded rescue procedure. The light-chain and Fd genes of a human tetanus toxoid-binding IgG Fab clone, described previously, ${ }^{(7)}$ were amplified by PCR, ligated together, and cloned into the SurfZAP lambda vector using the procedures described in the text. A pSurfScript Fab clone was excised, and phagemid particles were generated by infecting SOLR host cells with VCSM13. These phagemid particles were then reamplified by infecting XL1-Blue cells and growing in carbanicillin $(100 \mu \mathrm{g} / \mathrm{ml})$ until early to mid-log phase $(0.2-0.5$ $\mathrm{OD}_{600}$ ). The cells were gently pelleted and then resuspended in $1 \mathrm{ml}$ of fresh Luria-Burtani (LB) broth to an $\mathrm{OD}_{600}$ of 1.0. The cells were infected with VCSM13 helper phage (Stratagene) at a m.o.i. of 2:1 helper phage/host cells. The phage and cells were incubated at room temperature for $15 \mathrm{~min}$ and then diluted with $10 \mathrm{ml}$ of $\mathrm{LB}$ broth containing $100 \mu \mathrm{g} / \mathrm{ml}$ of carbenicillin and 50 $\mu \mathrm{g} / \mathrm{ml}$ of kanamycin. Single-stranded rescues were performed at $37^{\circ} \mathrm{C}(\boldsymbol{\square}), 30^{\circ} \mathrm{C}(\boldsymbol{\Delta})$, and $23^{\circ} \mathrm{C}$ (O). Aliquots of each culture were removed at the times indicated and centrifuged to remove cells; the supernatants were stored at $4^{\circ} \mathrm{C}$. $(A)$ The tetanus toxoid-binding activity of the phagemid that was measured in an ELISA assay using rabbit anti-M13 antisera (Stratagene). ${ }^{(11)}(B)$ The corresponding titers $(\mathrm{pfu} / \mathrm{ml})$ of the rescued phage samples.

found to inhibit Fab display at concentrations of $\geqslant 0.1 \%$ (vol/vol) unless removed prior to infection with helper phage (data not shown).

The most dramatic effect on Fab display, however, was noted when phagemid rescue was conducted at reduced temperature. Lowering the incubation temperature reduced the rate of cell growth and phage particle production but dramatically increased antigen-binding reactivity (Fig. 6). For example, phagemid particles recovered from $37^{\circ} \mathrm{C}$ cultures at $22 \mathrm{hr}$ and from $23^{\circ} \mathrm{C}$ cultures at $44 \mathrm{hr}$ exhibited approximately the same phage titer $(\mathrm{pfu} / \mathrm{ml})$ but dramatically different antigen-binding activities. These results suggest that lower temperature yields improved display phagemid, perhaps by reducing degradation of the Fab-cpIII protein or by aiding the assembly of Fabphagemid. Reduced growth temperature also allows a single-stranded rescue to be performed for a convenient period of time (e.g., overnight at $30^{\circ} \mathrm{C}$ or 2 days at room temperature). On the basis of these results, lower temperatures and optimal infection conditions have been implemented in preparing SurfZAP phagemid libraries for biopanning.

\section{Biopanning SurfZAP Fab Fragment Libraries}

Once the phagemid display library has been prepared by single-stranded rescue, clones that exhibit the desired binding activities can be enriched by biopanning. Typically, phagemid display libraries are incubated with antigen that is fixed on a polystyrene well ${ }^{(10-12,14,15,29)}$ or attached to chromatography resin. ${ }^{(29,37-40)}$ Alternatively, biopanning can be performed with whole cells that naturally bear antigen on the surface. ${ }^{(41-44)}$ Phagemid particles that do 
not bind to antigen are removed by extensive washes with, typically, Trisbuffered saline (TBS) containing a low concentration of nonionic detergent (e.g., TBS with $0.05 \%$ Tween 20 ). Specifically bound phagemid are then eluted by disrupting the antigen-antibody interaction with low $\mathrm{pH}^{(9-12,15)}$ high $\mathrm{pH}^{(29,37)}$ chaotropic agents, ${ }^{(38)}$ or the addition of competing free antigen. ${ }^{(18)}$ The eluted phagemid, which constitute an enriched population, are amplified and, if necessary, subjected to further cycles of biopanning/reamplification until satisfactory enrichment of antigen-specific clones is obtained. Antigen-binding activity of phagemid clones has been verified by plaque lifts with labeled antigen, ${ }^{(10-12,14,37)}$ ELISA, ${ }^{(10-15,17,19,29,37,38)}$ and electron microscopy. ${ }^{(12,14)}$

Previously, we have published the isolation of tetanus toxoid-binding clones from several SurfZAP Fab libraries by capturing specific phagemid with tetanus toxoid adhered to ELISA dish wells ${ }^{(10,11)}$ or coupled to Sepharose beads. ${ }^{(39,40)}$ As Figure 7 illustrates, panning efficiency, that is, the percent of antigen-specific binding clones recovered per panning cycle, can be influenced greatly by the method used to fix the antigen and to elute specific phagemid clones. In this experiment, eluates were significantly enriched in antigen-specific Fab clones after two cycles of biochromatography performed by low $\mathrm{pH}$ elution from antigen-coupled Sepharose beads. Significant, but lower, levels of enrichment were also observed after three cycles of biopan-

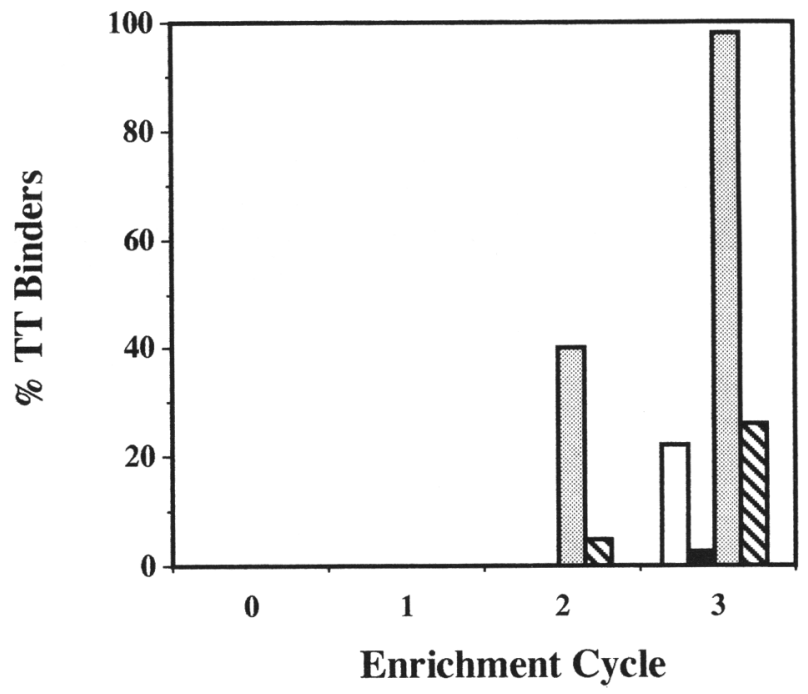

FIGURE 7 The effect of matrix and elution conditions on biopanning efficiency. A Fab phagemid display library was constructed as described in the text using peripheral blood lymphocytes from a human donor immunized against tetanus toxoid. Biopanning results are shown for phagemid purified as follows: (Shaded bar) Sepharose-TT column, low pH elution; (open bar) ELISA dish well, low pH elution; (striped bar) Sepharose-TT column, ethylene glycol elution; (solid bar) ELISA dish well, tetanus toxoid elution. Approximately $10^{10}$ phagemid particles were biopanned for 3 cycles in tetanus toxoid-coated $(1 \mu \mathrm{g} / \mathrm{ml})$ ELISA dish wells ${ }^{(11)}$ or by passage over tetanus toxoid-coupled Sepharose beads. Biochromatography was performed by applying phagemid particles, diluted in TBS containing $1 \mathrm{mg} / \mathrm{ml}$ of BSA, to an equilibrated $1-\mathrm{ml}$ column of Sepharose beads that had been coupled to tetanus toxoid (Connaught Labs) at $1 \mathrm{mg} / \mathrm{ml}$ using the manufacturer's recommended procedure (cyanogen bromide-activated Sepharose, Sigma). The column was washed with at least $100 \mathrm{ml}$ of the TBS/BSA buffer prior to elution of bound phagemid. In both the ELISA and biochromatography procedures, specifically bound phagemid was eluted at low $\mathrm{pH},{ }^{(11)}$ with $25 \%$ ethylene glycol, $75 \mathrm{mM}$ HEPES, and $3 \mathrm{M} \mathrm{MgCl}_{2}$, ${ }^{(38)}$ or in the presence of $10 \mu \mathrm{g} / \mathrm{ml}$ of tetanus toxoid. When ethylene glycol was used, the eluates were diluted prior to infecting bacteria. After infection with ethylene glycol or tetanus toxoid-eluted phagemid, the cells were gently pelleted and then resuspended in fresh media prior to VCSM13 infection. Single-stranded rescues were performed as described in the text, and the percentage of tetanus toxoid-binding Fab clones was determined with a plaque lift assay. ${ }^{(11)}$ 
ning perfomed with other combinations of elution conditions and matrices. We are currently evaluating the binding characteristics of Fab clones recovered under different elution conditions. It is anticipated that conditions for optimal enrichment efficiencies will vary depending on the constitution of the library and the particular antigen.

\section{DISCUSSION}

The methodologies described here and elsewhere ${ }^{(6,7,10-20,29,37,38)}$ for constructing libraries of $10^{8}$ clones have allowed the identification of a number of specific high-affinity Fab clones when the immunoglobulin sequences are derived by PCR from a biased B-cell source (e.g., spleen tissue from immunized mice, bone marrow or peripheral blood from immune humans). When an immunized B-cell source is not available, however, the identification of useful antibodies has been difficult. Our long-term goal is to create an easyto-use system for the rapid cloning of specific, high-affinity antibodies without the need for immunization. One potential solution is to increase the size of the antibody library, thereby increasing the probability of finding a rare clone with the desired binding characteristics.

Previous antibody libraries have been constructed by simultaneously introducing light- and heavy-chain genes into E. coli, either by plasmid transformation $^{(12-14,16,17,29)}$ or by bacteriophage infection. ${ }^{(6,7,10,11)}$ These methods effectively limit the size of antibody libraries to $10^{8}$ clones, which was an acceptable limit prior to the advent of phage display technology, which allows the rapid screening of $>10^{12}$ clones. To take advantage of the power of phage display screening, Waterhouse et al. ${ }^{(45)}$ have proposed an in vivo recombination method based on lox-Cre site-specific recombination. We have developed an alternative strategy by adapting the SurfZAP vector to a tandem expression system (Fig. 8). Rather than introducing light- and heavy-chain genes simultaneously as described above, diverse repertoires of light and heavy chains can be cloned into two different vectors for expression in the same cell. ${ }^{(13,46)}$ For example, we have introduced, by infection, a heavy-chain Fd library cloned in the SurfZAP phagemid vector into bacterial cells that contained a library of light chains in a plasmid vector. Bacterial infection is highly efficient; thus, the combinatorial diversity of Fab fragments displayed on phagemid should be the product of the size of the heavy-chain library multiplied by the size of the light-chain library. In this case, the resulting library size was limited by the number of bacterial cells cultured $\left(10^{11} /\right.$ liter $)$.

We have tested the tandem expression system described in Figure 8 by constructing a library of $10^{7} \mathrm{Fd}-\mu$ genes in the SurfZAP vector so that heavy chain is expressed as a fusion with cpIII and can be introduced into $E$. coli by phagemid infection. A library of $\lambda$ light chains, along with the necessary expression elements, was cloned onto a modified second vector containing a chloramphenicol gene ( $\mathrm{pBC}$, Stratagene). The light-chain library was introduced into XL1-Blue cells by transformation, and soluble light chains are produced in the periplasm of these cells. A library of $10^{4}$ chloramphenicolresistant transformants was amplified in 1-liter liquid cultures to produce $10^{11}$ cells $\left(10^{7}\right.$ copies of each of the $10^{4}$ light-chain clones). The cells were then infected with $2 \times 10^{11}$ ampicillin resistant phagemid $\left(2 \times 10^{5}\right.$ copies of each of the $10^{7} \mathrm{Fd}$ clones). Theoretically, cells grown under ampicillin and chloramphenicol selection would express $10^{11}$ different combinations of light chain and Fd. By infecting cells with VCSM13 as described above, phagemid particles displaying Fab were prepared that consisted of an approximately equal mixture of chloramphenicol-resistant (containing light-chain gene) and ampicillin-resistant (containing the Fd gene) phagemid.

The utility of this method for preparing large libraries was confirmed by 


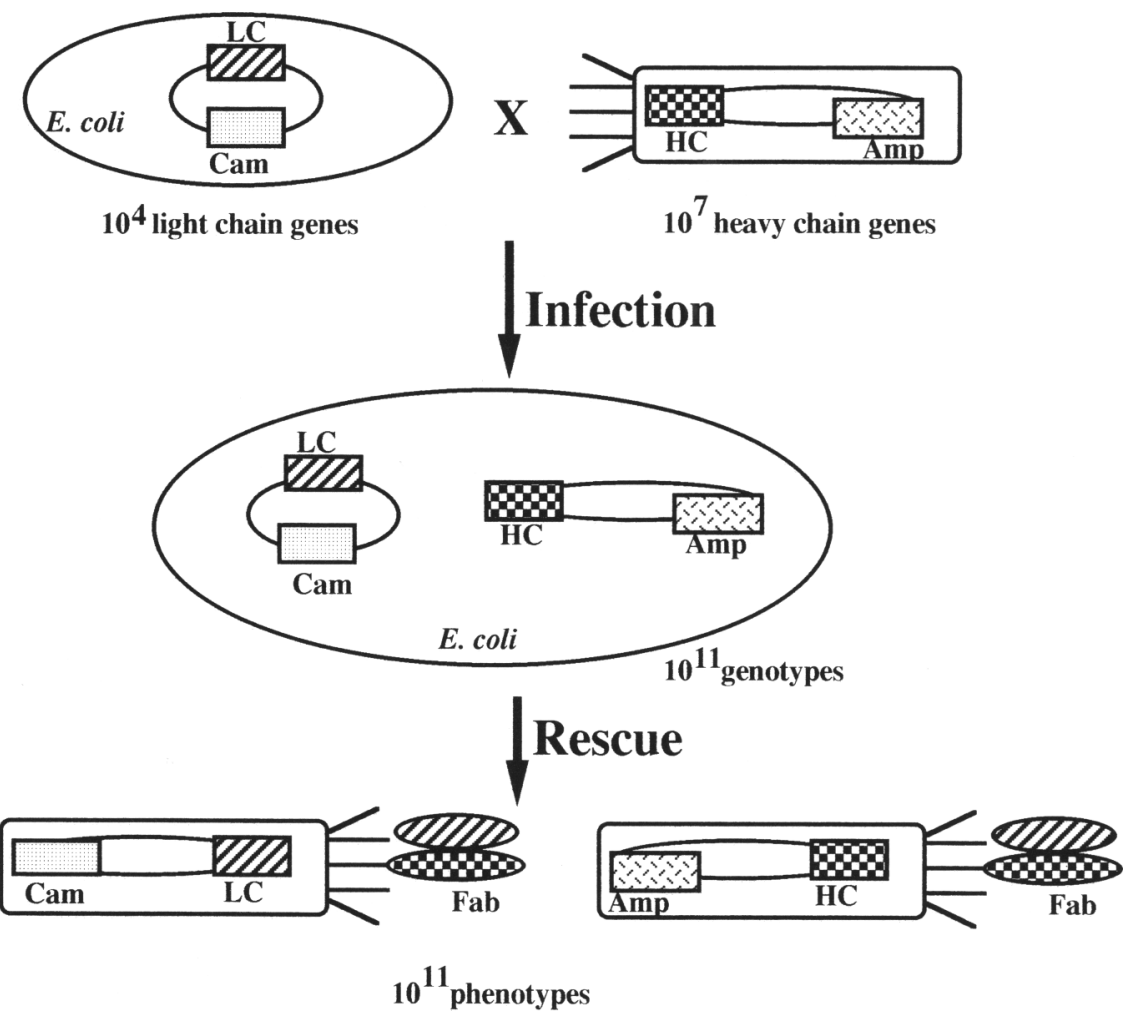

FIGURE 8 A tandem vector expression system for the construction of phage display libraries containing $10^{11}$ unique Fab clones. Libraries of light-chain genes (hatched rectangle) and Fd genes (checkered rectangle) are cloned into different vectors for expression in the same cell. The libraries are combined by infecting bacterial cells containing the light-chain plasmid library with phagemid containing the Fd library cloned into SurfZAP as a fusion with cpllI. Helper phage infection of ampicillin-resistant $\left(\mathrm{Amp}^{\mathrm{R}}\right)$ and chloramphenicol-resistant $\left(\mathrm{Cam}^{\mathrm{R}}\right)$ cells yields phagemid particles that display light chain (hatched rectangle in center oval) and Fd (checkered rectangle in center oval) on the surface, assembled into functional Fab. Phagemid generated by this method contain either the light chain encoding plasmid $\left(\mathrm{Cam}^{\mathrm{R}}\right)$ or the Fd-pSurfScript DNA $\left(A m p^{R}\right)$. Library size is determined as described in the text.

isolating tetanus toxoid-binding phage from a large-scale library $\left(10^{11}\right)$, which was deliberately spiked at frequencies of $10^{-5}-10^{-7}$ with a $\kappa$ light chain (expressed from plasmid) and a $\gamma 1$ Fd chain (expressed from SurfZAP) that were known to bind tetanus toxoid when paired (data not shown). We are currently characterizing the diversity of Fab clones in large-scale libraries constructed by this tandem expression method.

\section{ACKNOWLEDGMENTS}

We thank Amy Lovejoy, Bev Hay, Jeff Amberg, and Martin Gore, all formally of Stratacyte Corporation, for their contributions to this and previous work. We thank Mark Sullivan and Gary Barsomian for providing information that led to the design of a much improved set of mouse antibody primers. Human or mouse antibody primer sets can be obtained from Tera Biotechnology (B.S.). B.S. acknowledges assistance from the National Institutes of Health (AI32822, AI33250, CA59077, and CA57040).

\section{REFERENCES}

1. Skerra, A. and A. Pluckthun. 1989. Assembly of a functional immunoglobulin Fv fragment in Escherichia coli. Nature 341: 1038-1041.

2. Better, M., C.P. Chang, R.R. Robinson, and A.H. Horwitz. 1988. Escherichia coli secretion of 
an active chimeric antibody fragment. Science 240: 1041-1043.

3. Orlandi, R., D.H. Gussow, P.T. Jones, and G. Winter. 1989. Cloning immunoglobulin variable domains for expression by the polymerase chain reaction. Proc. Natl. Acad. Sci. 86: 38333837.

4. Larrick, J.W., L. Danielsson, C.A. Brenner, M. Abrahamson, K.E. Fry, and C.A.K. Borrebaeck. 1989. Rapid cloning of rearranged immunoglobulin genes from human hybridoma cells using mixed primers and the polymerase chain reaction. Biochem. Biophys. Res. Commun. 160: $1250-1256$.

5. Ward, E.S., D. Gussow, A.D. Griffiths, P.T. Jones, and G. Winter. 1989. Binding activities of a repertoire of single immunoglobulin variable domains secreted from Escherichia coli. $\mathrm{Na}$ ture 341: 544-546.

6. Huse, W.D., L. Sastry, S.A. Iverson, A.S. Kang, M. Alting-Mees, D.R. Burton, S.J. Benkovic, and R.A. Lerner. 1989. Generation of a large combinatorial library of the immunoglobulin repertoire on phage lambda. Science 246: 1275-1281.

7. Mullinax, R.L., E.A. Gross, J.R. Amberg, B.N. Hay, H.H. Hogrefe, M.M. Kubitz, A. Greener, M. Alting-Mees, D. Ardourel, J.M. Short, J.A. Sorge, and B. Shopes. 1990. Identification of human antibody fragment clones specific for tetanus toxoid in a bacteriophage lambda immunoexpression system. Proc. Natl. Acad. Sci. 87: 8095-8099.

8. Parmley, S.F. and G.P. Smith. 1988. Antibody-selectable filamentous fd phage vectors: Affinity purification of target genes. Gene 73: 305-318.

9. Scott, J.K. and G.P. Smith. 1990. Searching for peptide ligands with an epitope library. Science 249: 386-390.

10. Hogrefe, H.H., J.R. Amberg, B.N. Hay, J.A. Sorge, and B. Shopes. 1993. Cloning in a bacteriophage lambda vector for the display of binding proteins on filamentous phage. Gene 137: 85-91.

11. Hogrefe, H.H., R.L. Mullinax, A.E. Lovejoy, B.N. Hay, and J.A. Sorge. 1993. A bacteriophage lambda vector for the cloning and expression of immunoglobulin Fab fragments on the surface of filamentous phage. Gene 128: 119-126.

12. Barbas, C.F., A.S. Kang, R.A. Lerner, and S.J. Benkovic. 1991. Assembly of combinatorial antibody expression libraries on phage surfaces: The gene III site. Proc. Natl. Acad. Sci. 88: 7978-7982.

13. Burton, D.R., C.F. Barbas, M.A.A. Persson, S. Koenig, R.M. Chanock, and R.A. Lerner. 1991. A large array of human monoclonal antibodies to type I human immunodeficiency virus from combinatorial libraries of asymptomatic seropositive individuals. Proc. Natl. Acad. Sci. 88: 10134-10137.

14. Zebedee, S.L., C.F. Barbas, Y.-L. Hom, R.H. Caothien, R. Graff, J. Degraw, J. Pyati, R. Lapolla, D.R. Burton, R.A. Lerner, and G.B. Thornton. 1992. Human combinatorial antibody libraries to hepatitis B surface antigen. Proc. Natl. Acad. Sci. 89: 3175-3179.

15. Garrard, L.J., M. Yang, M.P. O'Connell, R.F. Kelley, and D.J. Henner. 1991. Fab assembly and enrichment in a monovalent phage display system. Bio/Technology 9: 1373-1377.

16. Hoogenboom, H.R., A.D. Griffiths, K.S. Johnson, D.J. Chiswell, P. Hudson, and G. Winter. 1991. Multi-subunit proteins on the surface of filamentous phage: Methodologies for displaying antibody (Fab) heavy and light chains. Nucleic Acids Res. 19: 4133-4137.

17. Orum, H., P.S. Andersen, A. Oster, L.K. Johansen, E. Riise, M. Bjornvad, I. Svendsen, and J. Engberg. 1993. Efficient method for constructing comprehensive murine Fab antibody libraries displayed on phage. Nucleic Acids Res. 21: 4491-4498.

18. Barbas, C.F., J.D. Bain, D.M. Hoekstra, and R.A. Lerner. 1992. Semisynthetic combinatorial antibody libraries: A chemical solution to the diversity problem. Proc. Natl. Acad. Sci. 89: 4457-4461.

19. Gram, H., L.-A. Marconi, C.F. Barbas, T.A. Collet, R.A. Lerner, and A.S. Kang. 1992. In vitro selection and affinity maturation of antibodies from a naive combinatorial immunoglobulin library. Proc. Natl. Acad. Sci. 89: 3576-3580.

20. Riechmann, L. and M. Weill. 1993. Phage display and selection of a site-directed randomized single-chain antibody Fv fragment for its affinity improvement. Biochemistry 32: 8848-8855.

21. Sastry, L., M. Alting-Mess, W.D. Huse, J.M. Short, J.A. Sorge, B.N. Hay, K.D. Janda, S.J. Benkovic, and R.A. Lerner. 1989. Cloning of the immunological repertoire in Escherichia coli for generation of monoclonal catalytic antibodies: Construction of a heavy chain variable region-specific cDNA library. Proc. Natl. Acad. Sci. 86: 5728-5732.

22. Larrick, J.W., L. Daniellson, C.A.B. Brenner, E.F. Wallace, M. Abrahamson, K.E. Fry, and C.A.K. Borrebaeck. 1989. Polymerase chain reaction using mixed primers: Cloning of human monoclonal antibody variable region genes from single hybridoma cells. Bio/Technology 7: 934-938.

23. LeBoeuf, R.D., F.S. Galin, S.K. Hollinger, S.C. Peiper, and J.E. Blalock. 1989. Cloning and sequencing of immunoglobulin variable-region genes using degenerate oligodeoxyribonucleotides and polymerase chain reaction. Gene 82: 371-377.

24. Marks, J.D., M. Tristem, A. Karpus, and G. Winter. 1991. Oligonucleotide primers for polymerase chain reaction amplification of human immunoglobulin variable genes and design 
of family-specific oligonucleotide probes. Eur. J. Immunol. 21: 985-991.

25. Sassano, M., M. Repetto, G. Cassani, and A. Corti. 1994. PCR amplification of antibody variable regions using primers that anneal to constant regions. Nucleic Acids Res. 22: 17681769.

26. Zhou, H., R.J. Fisher, and T.S. Papas. 1994. Optimization of primer sequences for mouse scFv repertoire display library construction. Nucleic Acids Res. 22: 888-889.

27. Hay, B.N., J.A. Sorge, and B. Shopes. 1992. Rapid conversion of a human hybridoma to expression of active Fab in E. coli by bacteriophage cloning. Hum. Antibodies Hybridomas 3: 81-87.

28. Kabat, E.A., T.T. Wu, M. Reid-Miller, H.M. Perry, and K.S. Gottesmann. 1987. Sequences of proteins of immunological interest, 4th ed., U.S. Department of Health and Human Services, U.S. Government Printing Services.

29. Marks, J.D., H.R. Hoogenboom, Y.P. Bonnert, J. McCafferty, A.D. Griffiths, and G. Winter. 1991. By-passing immunization: Human antibodies from V-gene libraries displayed on phage. J. Mol. Biol. 222: 581-597.

30. Short, J.M., J.M. Fernandez, J.A. Sorge, and W.D. Huse. 1988. Lambda ZAP: A bacteriophage lambda expression vector with in vivo excision properties. Nucleic Acids Res. 16: 7583-7600.

31. Harlow, E. and D. Lane. 1988. Antibodies: A laboratory manual. Cold Spring Harbor Laboratory, Cold Spring Harbor, New York.

32. Stevens, R.H., E. Macy, C. Morrow, and A. Saxon. 1979. Characterization of a circulating subpopulation of spontaneous antitetanus toxoid antibody producing B cells following in vivo booster immunization. J. Immunol. 122: 2498-2504.

33. Falkoff, R.J.M., L.-P. Zhu, and A.S. Fauci. 1983. The relationship between immunization and circulating antigen-specific plaque-forming cells. Cell. Immunol. 78: 392-399.

34. Borrebaeck, C.A.K., L. Daniellson, and S.A. Moller. 1988. Human monoclonal antibodies produced by primary in vitro immunization of peripheral blood lymphocytes. Proc. Natl. Acad. Sci. 85: 3995-3999.

35. Sambrook, J., E.F. Fritsch, and T. Maniatis. 1989. Molecular cloning: A laboratory manual. Cold Spring Harbor Laboratory Press, Cold Spring Harbor, New York.

36. Short, J.M. and J.A. Sorge. 1993. In vivo excision properties of bacteriophage lambda ZAPR expression vectors. Methods Enzymol. 216: 495-508.

37. McCafferty, J., A.D. Griffiths, G. Winter, and D.J. Chiswell. 1990. Phage antibodies: Filamentous phage displaying antibody variable domains. Nature 348: 552-554.

38. Chang, C.N., N.F. Landolfi, and C. Queen. 1991. Expression of antibody Fab domains on bacteriophage surfaces. J. Immunol. 147: 3610-3614.

39. Shopes, B. (in prep.).

40. Shopes, B. 1994. Human metaphoric antibodies from a phagemid library. In Antibody engineering, 2nd ed. (ed. C. Borrebaeck), Oxford University Press, New York. (In press.)

41. Marks, J.D., W. Ouwehand, J. Bye, B. Gorick, S. Thorpe, N.C. Hughes-Jones, and G. Winter. 1992. Human single chain $\mathrm{Fv}$ (scFv) antibody fragments against self and non-self erythroid carbohydrate and protein antigens isolated from a non-immune library of scFvs expressed on the surface of bacteriophage. Third Annual IBC Conference on Antibody Engineering: New technology and application implications, IBC, Southborough, MA.

42. Portolano, S., S. McLachans, and B. Rapport. 1993. High affinity thyroid specific human autoantibodies displayed on the surface of filamentous phage use V-genes similar to other autoantibodies. J. Immunol. 151: 2839-2851.

43. Siegal, D. and L. Silberstein. 1994. Expression and characterization of recombinant anti$\mathrm{Rh}(\mathrm{D})$ antibodies on filamentous phage: A model system for isolating human red blood cell antibodies by repertoire cloning. Blood 83: 2334-2344.

44. Barsomian, G., pers. comm.

45. Waterhouse, P., A.D. Griffiths, K.S. Johnson, and G. Winter. 1993. Combinatorial infection and in vivo recombination: A strategy for making large phage antibody repertoires. Nucleic Acids Res. 21: 2265-2266.

46. Gore, M., J. Amberg, and B. Shopes. 1992. Multiple partners: Promiscuous use of antibody light chains by a single heavy chain. Keystone Meeting, Monoclonal Antibodies, Denver, CO. 


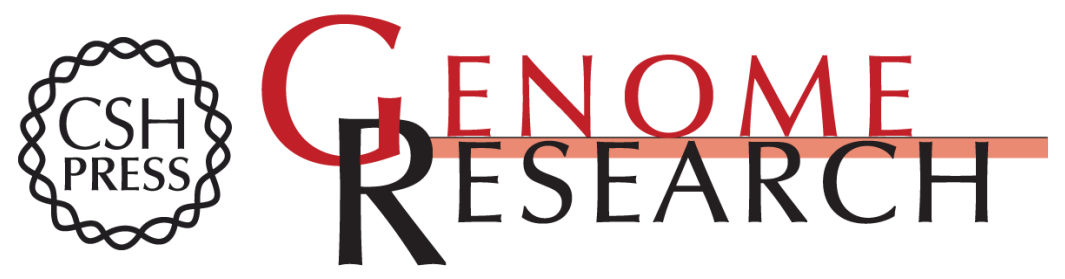

\section{Construction of phagemid display libraries with PCR-amplified immunoglobulin sequences.}

$\mathrm{H} \mathrm{H}$ Hogrefe and B Shopes

Genome Res. 1994 4: S109-S122

References This article cites 38 articles, 16 of which can be accessed free at: http://genome.cshlp.org/content/4/2/S109.full.html\#ref-list-1

License

Email Alerting Receive free email alerts when new articles cite this article - sign up in the box at the Service top right corner of the article or click here.

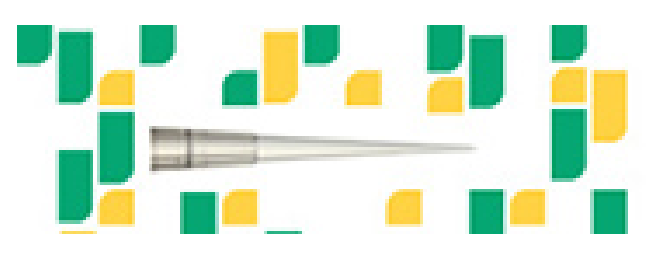

Focused on your science.

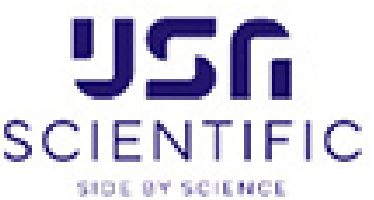

To subscribe to Genome Research go to:

https://genome.cshlp.org/subscriptions 